Article

\title{
Exploring Dockless Bikeshare Usage: A Case Study of Beijing, China
}

\author{
Zheyan Chen *, Dea van Lierop and Dick Ettema
}

Faculty of Geosciences, Utrecht University, 3508 TC Utrecht, The Netherlands; d.s.vanlierop@uu.nl (D.v.L.); D.F.Ettema@uu.nl (D.E.)

* Correspondence: z.chen1@uu.nl; Tel.: +31-30-253-1392

Received: 20 December 2019; Accepted: 6 February 2020; Published: 8 February 2020

\begin{abstract}
The rapid emergence of dockless bikeshare systems has had a considerable influence on individuals' daily mobility patterns. However, information is still limited regarding the role that sociodemographics, social environments, travel attitudes and the built environment play on the adoption and usage of dockless bikeshare systems. To gain insight into what influences individuals to start and continue to use dockless bikeshare systems, this study sets out to assess the influential factors that are related to individuals' initial adoption and frequency of usage of this transportation mode. A survey was conducted among the residents of Beijing to assess their usage of dockless bikeshare systems. A binary logistic regression is employed to assess travel mode adoption, and a set of hurdle negative binominal regressions is used to assess the travel frequency for four trip purposes. The results reveal that dockless bikeshare systems are more popular among younger, higher educated, or median-income groups and appear to be gender-independent. The total number of kilometers of roads within an individual's neighborhood was reported to be positively associated with having higher odds of dockless bikeshare adoption, while the total length of bicycle paths does not show a significant relationship. Having a pro-bicycle attitude was found to play a strong positive role in deciding whether to use the dockless bikeshare system initially, but it became less important in determining bikeshare users' frequency of usage. Finally, this study confirms that it is relevant to consider various trip purposes when exploring individuals' travel behavior and dockless bikeshare usage.
\end{abstract}

Keywords: dockless bikeshare; active transportation; cycling; travel behavior; travel attitudes

\section{Introduction}

In recent years, many municipal governments have developed policies that promote sustainable travel modes. At the same time, facilitated by rapidly developing information technology (IT), bikeshare systems have been widely adopted in many cities around the world [1,2]. Presently, two main service models of bikeshare exist, namely, docked and dockless. Docked bikeshare schemes first gained popularity in the late 1990s and require users to start and end trips at a bikeshare docking station. Dockless systems were developed as a response to the difficulty associated with accessing docking stations [3]. Since the 2010s, dockless bikeshare systems have become increasingly popular, first in China and then in the United Kingdom, Singapore, the United States, the Netherlands and in other locations [4]. The rapid emergence of dockless bikeshare schemes in many regions has had a considerable influence on individuals' daily mobility patterns [5]. However, dockless bikeshare systems are a relatively new phenomenon in many cities, and little is known about how, why and when individuals choose to use this form of mobility. Accordingly, gaining an improved understanding of how and by whom dockless bikeshare systems are used is of vital importance for transportation, urban research and policy interventions to promote active travel. 
Existing studies on docked bikeshare systems, as well as the cycling literature more generally, provide a foundation for the exploration of the usage of dockless bikeshare systems. Evidence on docked bikeshare systems and privately owned bicycle usage has revealed the non-negligible influence of individual characteristics, the social environment, travel attitudes and the built environment on cycling behavior. With regard to sociodemographic characteristics, existing studies on docked bikeshare systems have suggested that in many regions, younger, male, and wealthier populations account for a larger percentage of users [6-8]. Buck, Buehler [9] compared the demographic differences of Capital Bikeshare $(\mathrm{CaBi})$ users and users of regular bicycles in Washington, D.C. In contrast with the fact that two thirds of the DC regular cyclists were older than 35, the study revealed that over half of the $\mathrm{CaBi}$ annual members were between 25 and 34 years old. Gender differences have also been observed between bikeshare users and other cyclists. For example, the results of a study in Dublin showed that women accounted for merely $22 \%$ of the docked bikeshare users [10]. A study of Australian bikeshare programs has also found that $23 \%$ and $40 \%$ of the docked bikeshare annual members for Melbourne and for Brisbane respectively are women [11]. Meanwhile, registered female users of London's Cycle Hire Scheme took less than $20 \%$ of the total bikeshare trips in the first seven months of the scheme's operation from July 2010 [12]. As for income status, evidence from London, Washington and Hangzhou all suggested that docked bikeshare users tend to be wealthier than the general population [12-14]. Interestingly, however, Ogilvie and Goodman [13] also found that users in the most income deprived areas tended to make more shared bike trips ( 0.85 more trips per month) than those living in the highest average income areas when controlling for the fact that there were less docking systems in deprived areas.

Related to cycling in general, a significant association between social environment variables and cycling has been found in many studies. For example, Xing, Handy [15] found that a supportive social environment for cycling could strongly increase the likelihood of being a cyclist and the intention to use a bicycle for recreational purposes. Individuals are also found to engage in cycling more often when they have family or friends who engage in cycling [16]. Docked bikeshare systems have been found to be helpful in normalizing the image of cycling, thus creating an encouraging environment for viewing cycling as a core aspect of public transport provision [17]. Apart from the social environment, individuals' attitudes have been shown to directly impact the intention to participate and frequently use docked bikeshare systems [6]. A study on the Citycycle program in Brisbane claimed that most of the nonbikeshare users in the research sample had a pro-car attitude, and a preference for the experience of cycling was the most important reason for the respondents to be a member of Melbourne Bike Share (MBS) [11]. Kaplan, Wrzesinska [18], on the other hand, considered cycling from the perspective of fulfilling human needs and examined the intention to use bikeshare in three driving-oriented Polish cities: Poznan, Seczecin and Gorzow Wielkopolski. Respondents' attitudes towards cycling, whether they considered it as a tool to fulfill a sense of belonging, their self-actualization and their self-esteem were reported to be associated with a higher propensity to use conventional bikeshare. Heinen, Maat [19] concluded in their study of bicycle commute mode choice in the Netherlands that having a positive attitude towards cycling increased the likelihood of being a commuter cyclist. Ma and Dill [20] explored the influence of individuals' attitudes towards daily travel on general bicycling for transportation and found that having a pro-transit attitude was positively associated with the propensity to cycle and the frequency to cycle for transportation. Having a pro-environment attitude, which usually correlates with possessing a pro-bicycle attitude and an awareness of the physical benefits of cycling, is suggested to be positively associated with frequent bicycle usage $[21,22]$.

The ways that the built environment is related to travel behavior have also been exhaustively researched in the field of transportation. Compared with individuals' sociodemographics and attitudinal variables, built environment attributes have been found to have a smaller but still significant influence on cycling [15,23-25]. In spite of the fact that the residential self-selection process confounds the relationship [26,27], the predominant role of "five Ds"—density, diversity, design, destination 
accessibility and distance to transit $[23,28]$ on cycling behavior, is widely accepted. Earlier research already suggested that neighborhoods with high density, diversity and destination accessibility are commonly associated with lower levels of automobile usage and a higher proportion of nonmotorized trips [29,30]. In an analysis of cycling behavior in 36 British cities and towns, Cervero, Denman [31] did not find one single specific factor that was significantly associated with higher commute cycling, but rather, these authors found that commute cycling was collectively influenced by several factors including supportive bicycle networks (e.g., low-stress and noncircuitous bike paths), land use mix, urban amenities and specific local cycling culture and policy environments. Likewise, regarding the usage of docked bikeshare systems, frequently examined built environment characteristics around bikeshare docking stations, involving population density, job density, bicycle and public transit infrastructures, street designs, land-use mix, and proximity to central areas, were found to significantly influence the adoption or usage of docked bikeshare systems. Rixey [32] identified significant positive associations among population density and job density in the $400 \mathrm{~m}$ buffer of every docking station and the number of monthly rentals per station in three U.S. public bikeshare systems: Capital Bikeshare, Denver B-Cycle, and Nice Ride MN. Meanwhile, a positive correlation to the usage of shared bikes that the proximity to a large number of other bikeshare stations was found to show indicated the importance of comprehensive access to shared bikes (or docking stations) in encouraging bikeshare usage. However, the presence of bicycles lanes was found to be less significantly related to bikeshare ridership of all the examined three systems in this study than was found in the Buck and Buehler [33] analysis of Capital Bikeshare.

Since dockless bikeshare systems are relatively newly developed, there has been limited research on what influences people's usage of these systems. The Mobike report [34] and a study of the dockless bikeshare system in Nanjing, China [35] have examined the sociodemographics of dockless bikeshare users and both reported a higher proportion of users aged $19-40$ years than users of other ages. Mobike Global, Beijing Tsinghua Tongheng Planning and Design Institute [34] suggested that males tended to make more trips than females, and retired males were reported to ride the longest distance and have the highest riding speeds. Du and Cheng [35], however, found no large gender differences among users but reported that dockless bikeshare adoption was high among employees and college students due to their fixed working and education commuting needs. Unlike docked bikeshare systems, examining the association between bikeshare usage and built environment features cannot be done at the station level. Instead, exploring the built environment effects at the system level (built environment of the whole area where dockless bikeshare systems are operated) or at the individual level (built environment around the residential or working areas for each user) are alternatives to understanding this association for dockless bikeshare systems. One recent study on the primary dockless bikeshare system in Singapore [4] examined the ridership of a dockless bikeshare system at the system level by dividing the research area into grid cells and aggregating the built environment features and numbers of bike trips into each cell. They reported that a high land use density of commercial areas, small street blocks, supportive cycling facilities and better transportation infrastructure are associated with a higher average number of trips made per bike per day.

Nonetheless, insight into the role that sociodemographics, the built environment and travel attitudes play on the adoption and usage of dockless bikeshare systems and how this differs from docked bikeshare systems, remains limited. Therefore, further research in this area is necessary. First, more evidence on the association between sociodemographics and the usage of dockless bikeshare systems is needed to identify dockless bikeshare user groups. In addition, the effect that individuals' social environment and travel attitudes have on the usage of dockless bikeshare systems is still an underexplored area. Besides, the impact of the built environment on the usage frequency of dockless bikeshare systems has not been sufficiently focused on.

Another research gap is that limited research on bikeshare systems has considered individuals' tendencies to both (a) adopt bikeshare systems (to be a member of a certain bikeshare system) and (b) frequently use the service (how often users ride shared bikes). However, the factors that influence 
individuals' adoption and frequency utilization and the influential magnitudes of the corresponding factors can differ, as the research on general bicycling behavior has suggested [36]. For example, a study of cycling for transportation in Portland, Oregon found the lengths of bike lanes and minor streets are positively related to a higher tendency to cycle in the past month but have no association with cycling frequency [20]. The decoupling of individuals' adoption to dockless bikeshare systems and actual usage is relevant in the context of a transition from privately owned vehicles to shared mobility as a service.

Beyond the above-mentioned gaps, it is important to note that the use frequency of dockless bikeshare systems for different travel purposes can be influenced by divergent factors, and the influential direction, significance and magnitude level of these factors might also vary. Xing, Handy [15] explored the factors associated with general cycling for transportation and recreation in several US cities. Age was found to be positively associated with the miles of recreational cycling but not transportation cycling, while education was positively related to the miles of cycling for transportation instead of recreation. In addition, Beecham and Wood [37] suggested that female users of London's Cycle Hire Scheme engaged more in recreational cycling (such as visiting parks) than commuting travel. However, studies that thoroughly compare dockless bikeshare cycling among different trip purposes of daily travel are still lacking.

In order to assist in bridging these gaps, this research investigates the relationship between sociodemographics, social environment, travel attitudes, the built environment and dockless bikeshare adoption and usage. More specifically, this research sets out to explore the following research questions:

- To what extent do sociodemographics, social environment, travel attitudes and the built environment of residential neighborhoods influence individuals' tendency to adopt dockless bikeshare systems?

- To what extent do sociodemographics, social environment, travel attitudes and the built environment of residential neighborhoods influence dockless bikeshare users' frequency of using dockless shared bikes for the following four travel purposes: work or education commuting, sports and leisure, grocery shopping and recreational activities such as shopping, eating and drinking?

To answer these research questions, this study applies a quantitative approach to assess what influences individuals to adopt and frequently use dockless bikeshare systems for different trip purposes.

\section{Materials and Methods}

\subsection{Context}

The research area of this case study is the city of Beijing, China, which has a population of 21.5 million (as of the end of 2018). In June 2015, the first dockless bikeshare system started to appear in Beijing on the campus of Peking University. In 2016, dockless bikeshare systems extended outside the university and gained large popularity in other areas of Beijing and other major Chinese cities. These dockless systems combine cashless mobile payment and Global Positioning System tracking. All the necessary functions such as locating and unlocking a bike and payment are incorporated into a smartphone application. Considering that the rapid expansion of shared bikes exceeded the demands and triggered some social concerns (e.g., irregular parking), the Beijing Municipal Transportation Commission proposed to restrict the volume of shared bikes in the city. In August 2018, there were nine shared bicycle operators in Beijing, and the total number of operating vehicles has been controlled at 1.91 million. Nevertheless, in 2018, the average number of users per day reached 1.42 million in Beijing and over 10 million all over the country [38].

\subsection{Sampling and Data Collection}

To obtain the data required for this study, a comprehensive online questionnaire was designed for the residents of Beijing. This survey contained questions about individuals' sociodemographics, their 
social environment, travel attitudes towards different transportation modes, usage of the dockless bikeshare system and the use frequency of dockless shared bikes for several different trip purposes. Individuals who are under 16 years of age are not allowed to register to use the dockless bikeshare system and, therefore, were not included in the study. We hired a recruitment company in China (www.wjx.cn) to recruit potential participants by emailing questionnaires to randomly selected Beijing residents aged 16 years old and above. The gender distribution of the returned questionnaires was monitored to assure a relatively balanced percentage of male and female respondents. The data collection process was completed between 7 August 2018 and 31 November 2018. This period gives us a sufficient variety across weather conditions. A total of 606 valid questionnaires were obtained for analysis. The spatial data of the built environment are derived from two primary resources of land use information. One resource is the land use dataset of China including the Points-of-Interest (POIs) and road networks from the OpenStreetMap (OSM) updated in September 2018; the other resource is the public transit dataset of Beijing in November 2017 compiled by Urban Data Party (www.udparty.com).

Table 1 summarizes the characteristics of the participants. Dockless bikeshare users account for $80.7 \%(N=489)$ of the respondents $(N=606)$. The sample overrepresents bikeshare users (compared to nonusers) since approximately half of the population in Beijing were registered as dockless bikeshare members in 2017 [38]. This is likely due to an inclusion of "dockless bikeshare systems" in the title of the survey, which makes the survey less appealing to nonusers, although the introduction of the survey emphasized that the views of nonusers were important and appreciated. Although this sample might not be representative of the population in Beijing at large, more respondents of dockless bikeshare users are useful for targeting and analyzing the bikeshare share usage behavior. More than half of the respondents are between 16 and 30 years old, and most respondents have at least a Bachelors' degree. The sample contains mostly full-time employees. Over half of the respondents reported living in privately purchased or self-built houses. With regard to the accessibility to different travel modes, $72.1 \%$ of the respondents own at least one car. Of all respondents, the average network distance to the closest bus stop from respondents' home is approximately 330 meters, while the average distance to the closest subway station is approximately 3 kilometers. The majority (72\%) of the 489 dockless bikeshare users in the sample use the dockless bikeshare system for their daily commuting travel. Traveling for sports and leisure is another important travel purpose for which $56.6 \%$ of the bikeshare users among the whole research sample choose to use dockless systems. Even for grocery shopping and recreational activities, more than half of the users in the sample would turn to dockless bikeshare systems.

Table 1. Descriptive analysis of the variables.

\begin{tabular}{|c|c|c|}
\hline & $\%(N=606)$ & Mean (Std. Dev.) \\
\hline \multicolumn{3}{|l|}{ Dockless bikeshare usage } \\
\hline Users & $80.7 \%$ & \\
\hline Nonusers & $19.3 \%$ & \\
\hline \multicolumn{3}{|l|}{ Dockless bikeshare usage purposes among users } \\
\hline Work or education commuting & $72.4 \%(N=489)$ & \\
\hline Sports and leisure & $56.6 \%(N=489)$ & \\
\hline Grocery shopping & $51.1 \%(N=489)$ & \\
\hline Recreational activities (e.g., shopping, drinking, eating) & $53.8 \%(N=489)$ & \\
\hline \multicolumn{3}{|l|}{ Gender } \\
\hline Female & $51.0 \%$ & \\
\hline Male & $49.0 \%$ & \\
\hline \multicolumn{3}{|l|}{ Age (years) } \\
\hline $16-30$ & $59.9 \%$ & \\
\hline $31-45$ & $32.7 \%$ & \\
\hline $46-64$ & $7.4 \%$ & \\
\hline \multicolumn{3}{|l|}{ Education } \\
\hline High school/Secondary technical school and below & $5.0 \%$ & \\
\hline University/College Bachelors' degree & $72.1 \%$ & \\
\hline Master's degree and above & $22.9 \%$ & \\
\hline
\end{tabular}


Table 1. Cont.

\begin{tabular}{|c|c|c|}
\hline & $\%(N=606)$ & Mean (Std. Dev.) \\
\hline \multicolumn{3}{|l|}{ Household income } \\
\hline Low income (less than 12,000 yuan) & $31.0 \%$ & \\
\hline Median income (12,000-20,000 yuan) & $36.0 \%$ & \\
\hline High income (more than 20,000 yuan) & $33.0 \%$ & \\
\hline \multicolumn{3}{|l|}{ Employment } \\
\hline Full-time employment & $72.9 \%$ & \\
\hline Part-time employment, students, etc. & $27.1 \%$ & \\
\hline \multicolumn{3}{|l|}{ Housing situation } \\
\hline Private purchase/self-built & $51.5 \%$ & \\
\hline Employers' offer/student dormitory & $19.0 \%$ & \\
\hline Other & $29.5 \%$ & \\
\hline \multicolumn{3}{|l|}{ Car ownership } \\
\hline No & $27.9 \%$ & \\
\hline Yes & $72.1 \%$ & \\
\hline \multicolumn{3}{|l|}{ Self-reported health } \\
\hline Fair and below & $37.5 \%$ & \\
\hline Good & $34.7 \%$ & \\
\hline Very good and above & $27.9 \%$ & \\
\hline \multicolumn{3}{|l|}{ Spatial variables } \\
\hline \multicolumn{3}{|l|}{ Accessibility to trip attractions } \\
\hline Number of grocery stores in the neighborhood & & $1.57(3.140)$ \\
\hline Number of bars in the neighborhood & & $1.48(5.991)$ \\
\hline Number of restaurants in the neighborhood & & $3.9(8.982)$ \\
\hline Distance to closest shopping mall (km) & & $5.209(7.729)$ \\
\hline Distance to closest education facility $(\mathrm{km})$ & & $1.368(1.688)$ \\
\hline Number of education facilities in the neighborhood & & $0.45(1.489)$ \\
\hline Distance to closest entertainment facility (km) & & $5.021(6.848)$ \\
\hline Distance to closest sports facility $(\mathrm{km})$ & & $1.486(2.486)$ \\
\hline Distance to closest park $(\mathrm{km})$ & & $1.751(2.201)$ \\
\hline \multicolumn{3}{|l|}{ Design } \\
\hline The length of all roads in the neighborhood $(\mathrm{km})$ & & $13.44(6.469)$ \\
\hline The length of bicycle roads in the neighborhood $(\mathrm{km})$ & & $3.391(2.700)$ \\
\hline The length of pedestrian-priority roads in the neighborhood $(\mathrm{km})$ & & $3.909(3.159)$ \\
\hline \multicolumn{3}{|l|}{ Distance to transit } \\
\hline Distance to closest bus stop (km) & & $0.332(0.331)$ \\
\hline Distance to closest subway stop $(\mathrm{km})$ & & $3.232(7.575)$ \\
\hline
\end{tabular}

Note: "neighborhood" is identified as the area within a 600-m radius of the household.

\subsection{Methodology}

This study utilizes a binary logistic regression to examine the odds of adopting dockless bikeshare systems. In addition, to assess the frequencies of travel with dockless shared bikes for four different daily trip purposes, the study uses a set of hurdle negative binominal regressions. Prior to estimating the models, an explanatory factor analysis was applied to the original survey questions of the respondents travel attitude to reduce the numbers of observed variables into fewer dimensions. A principal component analysis with varimax rotation was used, and eight latent factors, as shown in Table 2, were extracted from 31 observed variables. Overall, $64.8 \%$ of the total variance was explained, and the Cronbach's $\alpha$ (Cronbach's $\alpha=0.726>0.7$ ) indicated an internal consistency among the indicators. 
Table 2. Factor loadings of travel attitude.

\begin{tabular}{|c|c|c|}
\hline Factors & Indicators & Loadings \\
\hline \multirow{6}{*}{ Pro-car } & I like driving & 0.715 \\
\hline & Without a car, I cannot handle my daily life & 0.678 \\
\hline & Owning a car allows me to do more & 0.812 \\
\hline & Owning a car gives me freedom & 0.821 \\
\hline & I do not have any alternative for car use & 0.732 \\
\hline & A car gives me prestige and status & 0.618 \\
\hline \multirow{4}{*}{ Pro-e-bikes/scooters } & I like riding e-bikes & 0.891 \\
\hline & If possible, I would rather use e-bikes than take public transportation & 0.911 \\
\hline & Riding e-bikes can sometimes be easier for me than other modes & 0.906 \\
\hline & I think that traveling by e-bike is safer than all other modes & 0.805 \\
\hline \multirow{5}{*}{ Pro-public transportation } & I like to use public transportation & 0.807 \\
\hline & If possible, I would rather use public transportation than drive & 0.731 \\
\hline & Public transit can sometimes be easier for me than other modes & 0.784 \\
\hline & Public transportation is unreliable & -0.532 \\
\hline & Traveling by public transit is safer than other modes & 0.456 \\
\hline \multirow{4}{*}{ Pro-bicycles } & I like cycling & 0.834 \\
\hline & If possible, I would rather cycle than take public transportation & 0.839 \\
\hline & Cycling can sometimes be easier for me than other modes & 0.843 \\
\hline & I think that traveling by bicycle is safer than all other modes & 0.726 \\
\hline \multirow{4}{*}{ Pro-walking } & I like walking & 0.782 \\
\hline & If possible, I would rather walk than take public transportation & 0.791 \\
\hline & Walking can sometimes be easier for me than other modes & 0.788 \\
\hline & I think that traveling by foot is safer than all other modes & 0.661 \\
\hline \multirow{4}{*}{ Pro-environment/health } & I'm concerned about the environmental impacts of my daily travel & 0.770 \\
\hline & I'm willing to change travel mode if it's good for the environment & 0.795 \\
\hline & I'm concerned about the health impacts of my daily travel & 0.691 \\
\hline & The trip to/from work is a useful transition between home and work & 0.537 \\
\hline \multirow{2}{*}{ Anti-public transportation } & Transferring to other buses or metros is annoying & 0.664 \\
\hline & It bothers me that public transportation is too crowded & 0.846 \\
\hline \multirow{2}{*}{ Anti-travelling } & Travel time is generally wasted time & 0.761 \\
\hline & I prefer to organize my errands so that I make as few trips as possible & 0.712 \\
\hline
\end{tabular}

The first regression (Model 1) employed a binary logistic regression (Table 3). The dependent variable, individuals' tendency to adopt dockless bikeshare systems, was derived from the survey question "are you a user of dockless shared bikes?" to include the respondents who use friends or families' accounts to ride shared bikes and to exclude the respondents who were registered as a user on the mobile application but do not consider themselves to be users because they no longer ride dockless shared bikes.

During the second step, we explored dockless bikeshare users' utilization of shared bikes for the following four travel purposes of daily activities: work or education commuting; sports and leisure; grocery shopping; and recreational activities such as shopping, eating and drinking. Four hurdle negative binominal regression models (Model 2.1, Model 2.2, Model 2.3, and Model 2.4, together named as Model 2) were employed to investigate dockless bikeshare users' frequency of using dockless shared bikes during a typical week for these four travel purposes. That is, a binary logistic model is employed to estimate whether the respondents use dockless shared bikes for one certain purpose or not. At the same time, for the respondents who use shared bikes for a certain purpose, a negative binominal model is used to explore their use frequency during a typical week. The negative binomial regression was chosen as there is an overdispersion for the count data of nonzero frequencies. Compared with a Poisson regression, the negative binominal regression has an extra parameter to model the overdispersion. 


\subsection{Variables}

The explanatory variables used in this research comprise the four categories of sociodemographics, social environment, travel attitude and neighborhood characteristics (Table 1). The sociodemographic variables derived from the survey include the attributes of the respondents and their households, such as age, gender, education level, employment status, housing situation, household income and car ownership. Health status was self-reported by the respondents through a five-point scale from "poor" to "excellent".

The social environment variable included in the analysis was adopted from Ma and Dill [20] and was assessed by the average score of the respondents' extent of agreement with the following five statements by using a five-point scale from "strongly disagree" to "strongly agree": (1) Most people who are important to me, for example, my family and friends, think that I should use dockless shared bikes more; (2) Most people who are important to me would support me in using dockless shared bikes more; (3) The people who I live with ride dockless shared bikes to get to places, such as errands, shopping and work/school; (4) Many of my friends ride dockless shared bikes to get to places, such as errands, shopping and work/school; and (5) Many of my coworkers/classmates ride dockless shared bikes to get to work/school.

In addition to the sociodemographics and social environment, we included the latent variable of respondents' travel attitudes. A comprehensive list of 8 extracted factors and 31 observed indicators can be found in Table 2 above. The respondents indicated their extent of agreement with these 31 statements by using a five-point scale from "strongly disagree" to "strongly agree".

The environmental independent variables, namely, neighborhood characteristics, were objectively captured. We adopted "Accessibility to trip attractions", "Design" and "Distance to transit" based on the " $5 \mathrm{D}$ " model [23] according to the data availability. "Accessibility to trip attractions" was captured by creating accessibility measures (amount or proximity) for eight individual destination-based land uses (namely, trip attractions) identified from the POIs in the land use dataset of China. The identification of these trip attractions, including grocery stores, shopping malls, restaurants, bar/café/bubble-tea stores, entertaining amenities (such as cinemas and theaters), educational facilities, sports facilities, parks and open spaces, was based on the relevance of using dockless shared bikes for different purposes. The measured indicators for "Design" include the total number of kilometers of all roads, bicycle roads and pedestrian-priority roads within the neighborhood. The neighborhood was identified as the area within a $600-\mathrm{m}$ radius of the household. The $600-\mathrm{m}$ buffer size was chosen according to the criteria that requires an average distance of 500 600 meters between bus stops in Beijing [39]. For "Distance to transit", the proximity to the closest bus stop and subway stop were measured by network distances (actual street networks) instead of an airline distance (a straight line) from the respondents' household location to the closest bus stop or subway stop. Instead of investigating all the environmental independent variables for all four models in the Model 2 group, purpose-specific accessibility measures of "Accessibility to trip attractions" were applied among Models 2.1, 2.2, 2.3 and 2.4 based on their relevance to different travel purposes (Table 4).

\section{Results}

\subsection{Descriptive Results}

According to a bivariate analysis of dockless bikeshare cycling frequency with the explanatory variables, dockless bikeshare systems are largely used for work or education commuting by our respondents. The average cycling frequency for commuting is 5.4 trips per week, which is approximately 4 times higher than for other purposes. Users with a low education level use dockless shared bikes an average of 8 times for commuting and 4 times for recreational activities per week, while users with a Masters' degree or higher cycle only 4.8 times for commuting and 2.2 times for recreational activities per week on average. 
Table 3. Binary logistic regression for the adoption of dockless bikeshare systems.

\begin{tabular}{|c|c|c|}
\hline \multicolumn{3}{|l|}{ Model 1} \\
\hline & Coefficient & Odds Ratio \\
\hline \multicolumn{3}{|l|}{ Variables } \\
\hline (Intercept) & -5.244 & $0.005^{* * *}$ \\
\hline Age & -0.051 & $0.950 * *$ \\
\hline Gender (Male) & -0.348 & 0.706 \\
\hline \multicolumn{3}{|l|}{ Education (ref = high school equivalent and below) } \\
\hline University/college Bachelors' degree & 1.643 & $5.173^{* *}$ \\
\hline Masters' degree and above & 1.496 & $4.464 *$ \\
\hline \multicolumn{3}{|l|}{ Household income (ref = low income) } \\
\hline Median income & 0.738 & $2.092 *$ \\
\hline High income & 0.386 & 1.471 \\
\hline \multicolumn{3}{|l|}{ Employment (ref = part-time employment, students, etc.) } \\
\hline Full-time employment & 1.278 & $3.590 * * *$ \\
\hline \multicolumn{3}{|l|}{ Living situation (ref = private purchase/self-built) } \\
\hline Employers' offer/student dormitory & 1.672 & $5.320 * *$ \\
\hline Other & 0.976 & $2.653 * *$ \\
\hline Car ownership (Yes) & 0.453 & 1.574 \\
\hline \multicolumn{3}{|l|}{ Self-reported health (ref = fair and below) } \\
\hline Good & 0.148 & 1.159 \\
\hline Very good and above & 0.425 & 1.529 \\
\hline Social environment & 1.169 & $3.218^{* * *}$ \\
\hline \multicolumn{3}{|l|}{ Travel attitude } \\
\hline Pro-car & 0.156 & 1.168 \\
\hline Pro-e-bikes/e-scooters & 0.059 & 1.060 \\
\hline Pro-public transportation & 0.262 & 1.300 \\
\hline Pro-bicycles & 1.004 & $2.729 * * *$ \\
\hline Pro-walking & -0.293 & $0.746 *$ \\
\hline Pro-environment/health & -0.126 & 0.882 \\
\hline Anti-public transportation & 0.095 & 1.100 \\
\hline Anti-travelling & 0.068 & 1.070 \\
\hline \multicolumn{3}{|l|}{ Spatial variables } \\
\hline \multicolumn{3}{|l|}{ Accessibility to trip attractions } \\
\hline Number of bars in the neighborhood & 0.097 & 1.102 \\
\hline Number of restaurants in the neighborhood & -0.042 & $0.959 *$ \\
\hline Number of education facilities in the neighborhood & -0.186 & $0.831 *$ \\
\hline Distance to closest sports facility $(\mathrm{km})$ & 0.036 & 1.037 \\
\hline Distance to closest park $(\mathrm{km})$ & 0.233 & $1.263 *$ \\
\hline \multicolumn{3}{|l|}{ Design } \\
\hline The length of all roads in the neighborhood $(\mathrm{km})$ & 0.105 & $1.111^{* *}$ \\
\hline The length of bicycle roads in the neighborhood $(\mathrm{km})$ & -0.064 & 0.938 \\
\hline \multicolumn{3}{|l|}{ Distance to transit } \\
\hline Distance to closest bus stop $(\mathrm{km})$ & -0.923 & $0.397 *$ \\
\hline Distance to closest subway stop (km) & -0.053 & $0.948 *$ \\
\hline \multicolumn{3}{|l|}{ Model statistics } \\
\hline Number of observations & \multicolumn{2}{|c|}{606} \\
\hline R square & \multicolumn{2}{|c|}{0.381} \\
\hline Nagelkerke & \multicolumn{2}{|c|}{0.499} \\
\hline ROC (area under the curve) & \multicolumn{2}{|c|}{0.897} \\
\hline
\end{tabular}

Note: ${ }^{\prime * * * \prime} p<0.001,^{\prime * * \prime} p<0.01,{ }^{‘ * \prime} p<0.05^{\prime}{ }^{\prime} p<0.1$. 
Table 4. Hurdle negative binominal regressions for the cycling frequencies for different purposes.

\begin{tabular}{|c|c|c|c|c|c|c|c|c|}
\hline & \multicolumn{2}{|c|}{$\begin{array}{l}\text { Model 2.1: } \\
\text { Work or Education Commuting }\end{array}$} & \multicolumn{2}{|c|}{$\begin{array}{c}\text { Model 2.2: } \\
\text { Sports and Leisure }\end{array}$} & \multicolumn{2}{|c|}{$\begin{array}{l}\text { Model 2.3: } \\
\text { Grocery Shopping }\end{array}$} & \multicolumn{2}{|c|}{$\begin{array}{c}\text { Model 2.4: } \\
\text { Recreational Activities }\end{array}$} \\
\hline & Count & Zero & Count & Zero & Count & Zero & Count & Zero \\
\hline \multicolumn{9}{|l|}{ Variables } \\
\hline (Intercept) & 0.765 . & -1.227 & $-1.198 *$ & $-3.197 * *$ & 0.497 & -1.399 & 0.020 & $-3.288^{* *}$ \\
\hline Age & -0.001 & $-0.036 *$ & 0.002 & -0.017 & 0.001 & 0.000 & -0.011 & 0.013 \\
\hline Gender (Male) & 0.117 & -0.116 & 0.057 & 0.208 & -0.111 & -0.018 & 0.051 & 0.279 \\
\hline \multicolumn{9}{|c|}{ Education (ref = high school equivalent and below) } \\
\hline University/college Bachelors' degree & -0.291 & -0.348 & -0.124 & $1.338^{*}$ & 0.090 & 0.397 & $-0.747^{* * *}$ & 0.323 \\
\hline Masters' degree and above & $-0.528 * *$ & -0.385 & -0.411 & 1.103 & -0.086 & 0.426 & $-1.015^{* * *}$ & -0.364 \\
\hline \multicolumn{9}{|l|}{ Household income $($ ref $=$ low income $)$} \\
\hline Median income & -0.071 & 0.386 & -0.018 & 0.019 & 0.020 & 0.015 & -0.079 & -0.230 \\
\hline High income & 0.013 & 0.234 & 0.157 & -0.014 & 0.058 & 0.052 & $0.267 *$ & 0.124 \\
\hline \multicolumn{9}{|c|}{ Employment (ref = part-time employment, students, etc.) } \\
\hline Full-time employment & $-0.235 *$ & 0.184 & -0.202 & $0.659 *$ & 0.281 & -0.357 & $0.461 *$ & -0.173 \\
\hline \multicolumn{9}{|c|}{ Living situation (ref = private purchase/self-built) } \\
\hline Employers' offer/student dormitory & -0.174 & 0.127 & -0.019 & 0.714 & 0.152 & -0.644 & 0.261 & 0.439 \\
\hline Other & 0.141 & 0.059 & 0.197 & -0.194 & -0.157 & -0.124 & -0.031 & 0.014 \\
\hline Car ownership (yes) & 0.061 & 0.373 & $0.296 *$ & $0.523 *$ & $0.515^{* *}$ & 0.055 & -0.061 & -0.237 \\
\hline \multicolumn{9}{|l|}{ Self-reported health (ref = fair and below) } \\
\hline Good & 0.155 . & 0.198 & $0.260 *$ & $0.479 *$ & -0.186 & 0.137 & 0.087 & 0.009 \\
\hline Very good and above & 0.076 & $0.658^{*}$ & 0.030 & 0.066 & -0.228 & -0.007 & 0.069 & -0.316 \\
\hline Social environment & $0.302 * * *$ & $0.805^{* * *}$ & $0.444^{* * *}$ & $0.531 * *$ & -0.057 & 0.286 & 0.257 * & $0.789 * * *$ \\
\hline \multicolumn{9}{|l|}{ Travel attitude } \\
\hline Pro-car & $-0.134^{* * *}$ & $-0.287 *$ & -0.022 & 0.099 & -0.125 & 0.044 & 0.008 & $0.264 *$ \\
\hline Pro-e-bikes/e-scooters & -0.001 & $0.246^{*}$ & 0.065 & 0.001 & 0.031 & 0.080 & -0.016 & -0.006 \\
\hline Pro-public transportation & 0.020 & 0.228 & -0.018 & -0.019 & 0.010 & 0.132 & 0.098 & 0.072 \\
\hline Pro-bicycles & $0.120 *$ & 0.188 & 0.020 & 0.187 & 0.092 & 0.191 & 0.019 & 0.271 * \\
\hline Pro-walking & -0.040 & -0.184 & 0.093 & -0.033 & 0.110 . & -0.142 & 0.065 & -0.027 \\
\hline Pro-environment/health & -0.031 & 0.221 & -0.018 & 0.274 * & 0.067 & -0.065 & -0.001 & -0.107 \\
\hline Anti-public transportation & 0.062 & -0.194 & 0.004 & 0.022 & -0.072 & 0.022 & $0.152^{* *}$ & 0.171 \\
\hline Anti-travelling & -0.062 & -0.039 & $-0.123 *$ & $-0.262 *$ & -0.101 & $-0.255 *$ & -0.038 & $-0.216^{*}$ \\
\hline
\end{tabular}


Table 4. Cont

\begin{tabular}{|c|c|c|c|c|c|c|c|c|}
\hline & \multicolumn{2}{|c|}{$\begin{array}{c}\text { Model 2.1: } \\
\text { Work or Education Commuting }\end{array}$} & \multicolumn{2}{|c|}{$\begin{array}{l}\text { Model 2.2: } \\
\text { Sports and Leisure }\end{array}$} & \multicolumn{2}{|c|}{$\begin{array}{l}\text { Model 2.3: } \\
\text { Grocery Shopping }\end{array}$} & \multicolumn{2}{|c|}{$\begin{array}{c}\text { Model 2.4: } \\
\text { Recreational Activities }\end{array}$} \\
\hline & Count & Zero & Count & Zero & Count & Zero & Count & Zero \\
\hline \multicolumn{9}{|l|}{ Spatial variables } \\
\hline \multicolumn{9}{|l|}{ Accessibility to trip attractions } \\
\hline Number of grocery stores & 0.039 * & -0.015 & & & -0.010 & 0.062 & -0.035 & 0.057 \\
\hline Number of bars & -0.013 & 0.007 & & & & & 0.006 & 0.025 \\
\hline Number of restaurants & & & & & & & 0.002 & -0.030 \\
\hline Distance to closest shopping mall & & & & & -0.019 & -0.004 & -0.007 & -0.028 \\
\hline Distance to closest education facility & 0.047 & 0.072 & & & & & & \\
\hline $\begin{array}{l}\text { Distance to closest entertainment } \\
\text { facility }\end{array}$ & & & 0.015 & 0.001 & & & $0.035^{*}$ & 0.017 \\
\hline Distance to closest sports facility & & & 0.027 & 0.048 & & & & \\
\hline Distance to closest park & & & 0.032 & -0.047 & & & & \\
\hline \multicolumn{9}{|l|}{ Design } \\
\hline The length of all roads & -0.009 & -0.027 & 0.008 & -0.044 & 0.005 & 0.027 & 0.024 & 0.003 \\
\hline The length of bicycle roads & -0.020 & 0.109 & -0.044 & -0.001 & 0.014 & -0.061 & 0.046 & -0.100 \\
\hline $\begin{array}{l}\text { The length of pedestrian-priority } \\
\text { roads }\end{array}$ & 0.039 . & -0.046 & 0.018 & 0.063 & -0.032 & -0.002 & $-0.062 *$ & 0.083 \\
\hline \multicolumn{9}{|l|}{ Distance to transit } \\
\hline Distance to closest bus stop & -0.129 & -0.059 & -0.168 & -0.486 & -0.220 & -0.180 & -0.256 & 0.103 \\
\hline Distance to closest subway stop & $-0.016 *$ & -0.034 & -0.026 & -0.004 & 0.023 * & 0.019 & -0.013 & 0.009 \\
\hline \multicolumn{9}{|l|}{ Model statistics } \\
\hline Log(theta) & $1.553^{* * *}$ & & $2.346^{* * *}$ & & $2.59 * * *$ & & 3.827 * & \\
\hline $\mathrm{N}$ of cases & 489 & & 489 & & 489 & & 489 & \\
\hline AIC & 2320.88 & & 1644.77 & & 1531.55 & & 1520.02 & \\
\hline
\end{tabular}

Note: ${ }^{‘ * * * \prime} p<0.001,{ }^{* * * \prime} p<0.011^{\prime * \prime} p<0.05^{\prime \prime}$ 'p $p<0.1$. 


\subsection{Model Results}

This section provides an interpretation of the research findings by comparing the explanatory variables of Models 1 and 2. The Variances Inflation Factor (VIF) was calculated for Model 1 and Model 2, and the values in all models are less than 5, indicating no multicollinearity. In addition, to improve the performance of Model 1, several environmental variables that did not show a significant association (e.g., the length of pedestrian-priority roads in the neighborhood) were dropped from the model. The goodness-of-fit statistics for Model 1 are displayed in Table 3. In Model 1, the Nagelkerke $\mathrm{R}$ square is 0.499 and the value of the area under the ROC curve (AUC) is 0.897 , which suggests a good model performance. To test the goodness-of-fit for Model 2, we used chi-squared test on the difference of log likelihoods to compare with the current models (Model 2.1-2.4) to the corresponding null models without predictors. The $\mathrm{p}$ values $<0.05$ were reported for Model 2.1-2.4, suggesting Model 2 is statistically significant at the given cutoff.

Tables 3 and 4 display the regression results of Model 1 and Models 2.1 to 2.4. In Table 4, the "Zero" columns under Models 2.1 to 2.4 represent the coefficients and significance levels of the binary logistic modeling results to estimate the respondents' propensity to use dockless shared bikes in the hurdle negative binominal model, and the "Count" columns refer to the coefficients and significance levels of the negative binominal modeling results to estimate the respondents' frequency to use dockless shared bikes in the hurdle negative binominal model.

\subsubsection{Sociodemographics and Social Environment}

The results revealed that there is a strong association between individuals' sociodemographics and their tendency to adopt dockless bikeshare systems. Younger and higher educated individuals have a larger likelihood to be dockless bikeshare users. The odds of adopting dockless bikeshare systems for the respondents with a median household income were found to be $109 \%$ higher than the odds for the respondents with a low household income; however, no significant difference on the tendency to adopt dockless bikeshare systems exists between the respondents with a high household income and a low income. Additionally, compared with other types of employment (e.g., students, part-time employed workers, etc.), the odds of adopting dockless shared bikes increase $259 \%$ for full-time employed workers. Although previous research has suggested a higher likelihood of males to be bicycle riders, e.g., [12], there is no significant difference in the likelihood to adopt a dockless bikeshare system between male and female residents in this research.

In contrast, for the dockless bikeshare users among our respondents, the sociodemographic variables do not demonstrate a consistent association with their propensity and frequency to use dockless shared bikes among different travel purposes. The frequency of bikeshare trips for grocery shopping is not strongly associated with sociodemographics in general compared with the other three purposes. Among the four travel purposes, age displays a negative association with users' cycling propensity only for commuting. However, although higher educated dockless bikeshare users are also found to be more likely to use dockless shared bikes for sports and leisure, they ride shared bikes less often for commuting and recreational activities. Users who are employed full-time in our study tend to use dockless bikeshare systems less often for commuting but more often for recreational activities.

Although no significant impact of car ownership or an individual's self-reported health condition was suggested on the respondents' tendency to adopt dockless bikeshare systems, car ownership was found in Model 2 to present a significant association with the frequent usage of dockless shared bikes. The dockless bikeshare users with a car were found to have a higher cycling propensity and frequency for sports and leisure and a higher cycling propensity for grocery shopping is also revealed among the dockless bikeshare users with a car. Meanwhile, the users with better self-reported health have a higher propensity and frequency to use dockless shared bikes for both commuting and sports and leisure. Having a social environment that is supportive to dockless bikeshare systems, as expected, is a strong indicator of dockless bikeshare usage behaviors. The odds of the respondents' tendency to adopt dockless bikeshare systems increase by $221.8 \%$ with one-unit increase in social environment score. 
An individual's social environment also has a significantly positive association with users' propensity and frequency to use dockless shared bikes for all trip purposes except for grocery shopping.

\subsubsection{Travel Attitude}

Individuals' travel attitudes were found to significantly explain dockless bikeshare adoption and users' cycling frequency among different travel purposes. A pro-bicycle attitude shows an expected strong positive impact on the tendency to adopt dockless bikeshare systems, with an influential level much higher than other attitudinal factors, while people with a pro-walking attitude are less likely to be a dockless bikeshare user. In Model 2, when attempting to explain users' dockless bikeshare cycling propensity and frequency for different purposes, having a pro-bicycle attitude, surprisingly, does not exhibit a strong significant power. A pro-bicycle attitude shows a positive and relatively strong association with the cycling frequency for commuting trips but not for other purposes, and there is a positive correlation with users' propensity to use shared bikes only for recreational activities. This suggests that having a pro-bicycle attitude plays a strongly positive role in the decision to start using the dockless bikeshare systems initially but becomes less important in individuals' usage of dockless shared bikes for different purposes.

Among all four cycling purposes, travel attitude is strongly associated with using dockless shared bikes for commuting, and the least related to the usage of bikeshares for grocery shopping. For commuting trips, users with a pro-bicycle attitude tend to have a higher use frequency, and a pro-e-bike/e-scooter attitude plays an encouraging role in terms of the propensity to use shared bikes for commuting. A one-unit increase in the score of pro-bicycle attitude is associated with the expected $\log$ count of use frequency increasing by 0.12 , and the log odds of the propensity to use shared bikes for commuting increase by 0.246 for a one-unit increase in pro-e-bike/e-scooter. In contrast, users with a pro-car attitude are less likely to use dockless shared bikes for daily commuting, and they also use them less often. For every one-unit increase in pro-car attitude, we expect to see a $25 \%(1-\exp (-0.287))$ decrease in the odds of adopting dockless bikeshare systems for daily commuting and the log count of use frequency decreasing by 0.134 . Although in Model 1 the pro-environment/health attitude was not found to play a significant role for the respondents to adopt a dockless bikeshare system, it encourages people to use dockless shared bikes for sports and leisure activities, consistent with previous findings, e.g., [21]. For recreational trips, users' attitude towards public transportation plays an important role: users who think public transportation is crowded tend to have higher frequencies of dockless bikeshare usage. These results suggest that various travel attitudinal factors that can have an association with cycling propensity and frequency, as a matter of fact, largely rely on the trip purposes.

Interestingly, dockless bikeshare users with a pro-public transportation attitude were found to have a higher propensity to choose dockless bikeshare in their commuting trips, and users with an anti-public transportation attitude were marginally more likely to use shared bikes for this purpose. Similarly, both pro-public transportation and anti-public transportation attitudes have a positive association with the use frequency of dockless shared bikes for recreational activities. The similar encouraging effects of pro-public transportation and anti-public transportation attitudes might suggest a combination of a substitution and integration relation between public transportation and dockless bikeshare systems.

\subsubsection{Built Environment}

One aim of this study is to determine whether the built environment of individuals' residential neighborhood has any bearing on their usage of dockless bikeshare systems. In Model 1, two indicators for "Accessibility to trip attractions" - the number of education buildings and the number of restaurants in the neighborhood-were found to have a negative impact on the respondents' tendency to adopt dockless systems. This finding could be because a higher number of education buildings indicates the existence of many students on streets during peak hours, which might not be an appealing environment for residents to use shared bikes. In this case study, areas with a large number of restaurants usually 
correlate to a high land-use mix and density, which means that many places are easily accessible on foot and that the densest neighborhoods might not be perceived as being convenient for cycling and parking shared bikes.

The results of Model 2 suggest that "Accessibility to trip attractions" captures some associations only with the cycling frequencies for commuting and recreational activities. Higher numbers of grocery stores were found to be associated with more rides of dockless shared bikes for commuting. It could be that neighborhoods with more grocery stores tend to have a higher accessibility to shared bikes. Another possible explanation might be that taking a dockless shared bike is convenient for doing some grocery shopping on certain longer commuting trips. In addition, a higher distance to the closest entertainment facility is found to be associated with a higher frequency of dockless bikeshare use for recreational purposes.

Regarding "Design", a higher number of kilometers of all roads within the residential neighborhood was reported to be associated with a higher tendency to adopt dockless bikeshare systems, while the total length of bicycle roads in the neighborhood does not seem to show a significant relation. This is probably because in Beijing, separated bicycle paths are not yet common in the majority of situations, and bicycles and motorized vehicles share one road with a dashed line painted on the ground for separation. In contrast, for dockless bikeshare cycling for various trip purposes, the length of bicycle roads tends to display a marginally positive association with the propensity to use shared bikes for commuting but a negative association with recreational travel.

The distance to the closest bus stop and distance to the closet subway stop, which are indicators of "Distance to transit", are significant correlates. People who live in the neighborhood with a greater distance to bus stops and subway stops are less likely to become users of dockless bikeshare systems. This could be because the distance to public transit is beyond the sphere of using dockless bikeshare systems for the "first/last mile" of the trip. A higher distance to the closest subway stop is associated with a lower use frequency of dockless shared bikes for daily commuting but a higher use frequency for grocery shopping trips. This result might be determined by the nature of different trip purposes. There is a situation when dockless bikeshare trips for commuting purposes are mainly partial trips to connect subway stops to their destinations. If the distance to the closest subway stop exceeds the sphere of the "first/last mile" connection by dockless bikeshare systems, the frequency of shared bike trips for commuting also drops. The bikeshare trips for grocery shopping could be a substitute for using the subway, as when the distance to a closest subway stop is greater, people are less likely to take the subway for groceries and they might turn to shared bikes more often.

\section{Discussion and Conclusion}

\subsection{Dockless Bikeshare Users}

The majority of the literature on traditional docked bikeshare systems has suggested that males are more likely to be bikeshare users [12,13]. However, dockless bikeshare cycling in Beijing appears to be more gender-independent, which resembles what Du and Cheng [35] found in the study of the dockless bikeshare system in Nanjing. Fishman [6] indicated that although docked bikeshare users are more likely to be male, the gender disparity is smaller compared with users of private bicycles. Our research adds to this knowledge and indicates that dockless bikeshare systems might be an even better approach than docked bikeshare systems to engage females in cycling for daily travel. Nonetheless, dockless bikeshare systems seem to be more popular among young, higher educated and median-income groups. The usage of dockless systems is also relatively prevalent among full-time employees. In addition, dockless bikeshare users tend to have a strong positive attitude toward bicycles, and they are more likely to be surrounded by friends and family who use shared bikes, similarly to docked bikeshare riders and general cyclists [20,29]. 


\subsection{Attitudinal and Environmental Correlates}

Individuals' travel attitudes and the neighborhood-built environment were confirmed in the results to display an explanatory power in capturing the usage of dockless bikeshare systems. Contrary to individuals with a pro-bicycle attitude, individuals with a pro-walking attitude were found to be less likely to be dockless bikeshare users in our research. This reversed influential direction possibly indicates an existence of a substitution relationship between walking and using dockless shared bikes. This finding echoes previous evidence that suggests that in many regions, the majority of docked bikeshare trips were mainly found to be a substitute for walking or public transit trips [6]. In addition, the supportive effects of pro-public transportation and anti-public transportation attitudes on bikeshare users' cycling behaviors for commuting and recreational purposes in our research suggest a combination of a substitution and integration relation between public transportation and dockless bikeshare systems. Two different groups of users may explain these seemingly contradictory results: one group with more of a pro-public transportation attitude might be the users who ride shared bikes as the "first/last mile" integration to public transit or transfer in-between the transit stations, and the other group with an anti-public transportation attitude might use dockless shared bikes mostly to substitute for the trips taken by public transportation. This integration with public transit suggests that dockless bikeshare systems resemble traditional docked systems in increasing the catchment area and the efficiency of public transit networks and in bridging the gap between existing transportation networks [40-42].

With regard to the built environment, this study explores the relationship between "Accessibility to trip attractions", "Design" and "Distance to transit" as well as the usage of dockless shared bikes. Due to the availability of data, the traditionally widely examined "Density" and "Diversity" were not included in this investigation. However, our results suggest that the "Accessibility to trip attractions" variable can act as a proxy for the density and land-use mix of the neighborhood. For example, a higher number of restaurants in the neighborhood were found to be related to lower odds of being a shared bike user, which could suggest that neighborhoods with a high number of restaurants represent a higher density or the location of a central commercial area, whereas many places are easily accessible on foot, and shared bike parking is not easy due to pedestrian crowding. These findings are aligned with the results of a previous study in which Ewing and Cervero [23] indicated that density was likely to be an indicator often expressed by other " $\mathrm{D}$ "s when they found a relatively weak relationship between density and travel in their meta-analysis of empirical studies on travel and the built environment.

Previous studies have suggested a positive association between supportive cycling facilities and/or the presence of bicycle lanes and bikeshare cycling frequencies at the bike or station level, e.g., [4]. This study extended this knowledge by examining the cycling propensity and frequency of a dockless bikeshare system at the individual level. We found a marginally significant positive relationship between the length of cycling roads and dockless bikeshare users' cycling frequency for commuting trips but a negative association for recreational trips. In contrast, the total length of cycling roads in the neighborhood does not seem to have a significant association with dockless bikeshare system adoption, which is different from what Ma and Dill [20] found for general cycling behavior, namely, that the lengths of bicycle lanes are positively related to a higher tendency to cycle for transportation.

\subsection{Membership vs. Use Frequency}

To the authors' knowledge, this study is the first to consider both individuals' membership and the use frequency of dockless bikeshare. By examining both of these factors, we can provide a thorough comparison for further insights, which is limited in the current bikeshare literature. When comparing the influential magnitudes of travel attitude, this study revealed that having a pro-bicycle attitude plays a strong positive role in deciding whether to adopt or start using a dockless bikeshare system initially but becomes less important in determining bikeshare users' cycling propensity and frequency for different purposes. This finding reflects that a preference for bicycles can be a good intention for individuals to become a dockless bikeshare user, which requires a relatively low commitment. 
However, to become loyal to using the dockless bikeshare systems and highly incorporate them into daily travel takes more than good intentions. This gap might only exist among the users of dockless bikeshare systems, as the less flexible subscription service for docked bikeshare systems and the cost for bicycle ownership of privately owned bicycles both require a higher commitment to engage as a member.

\subsection{The Usage of Dockless Shared Bikes for Different Purposes}

Instead of focusing only on cycling for commuting or overall cycling regardless of purpose in previous studies, e.g., [29], we grouped dockless bikeshare users' cycling behavior according to various travel purposes. In this way, we attempted to contribute to the lack of comparison among different purposes in the general cycling and docked bikeshare literature. In general, dockless bikeshare systems are found to be largely used in work or education commuting trips. The average cycling frequency for commuting is approximately four times higher than for other purposes. In addition, sociodemographics, social environment, travel attitude and built environment associate with the usage propensity and frequency differently according to various travel purposes. Users' travel attitudes towards divergent travel modes, for instance, do not show much association with cycling for grocery shopping and for sports and leisure compared with commuting and recreation. In particular, among all four travel purposes, using shared bikes for grocery shopping is the least likely to relate to all examined explanatory variables. A supportive social environment for dockless bikeshare systems and the accessibility to trip attractions and road networks associate with neither the cycling propensity nor the cycling frequency for this purpose. This might be because the nature of travelling for groceries makes it less likely to be influenced by physical and social environmental factors. The decision to choose cycling largely depends on the availability of dockless shared bikes or the weight of groceries to carry during the trip, rather than friends and families' support and the built environment. Therefore, it is important for transportation researchers to consider travelling purposes when exploring the travel behavior of bikeshare system users.

\section{Limitations and Future Studies}

This research, however, is subject to several limitations. First, the restricted spatial data prevents a comprehensive investigation of the "Density" and "Diversity" of the built environment, and spatial data that involve more precise trip attractions can improve the measurement of the accessibility to trip attractions. In addition, this study measures the built environment at the residential neighborhood scale, while some cycling behavior such as cycling for commuting could be influenced by areas beyond the residential neighborhood. Third, considering the length of the questionnaire, this study applied an online recruitment approach. Yet, this method can be limited in accessing individuals who do not subscribe to the recruitment service, individuals with limited time as well as those who experience difficulties with online platforms. Fourth, our research sample is slightly skewed to dockless bikeshare users and higher educated individuals; however, the sample size enabled a meaningful analysis. Future research could consider better engaging nonusers and lower educated residents. This study suggests several research directions for future studies. As evidence from the Vélib' docked bikeshare system suggested, there exists a close connection between docked bikeshare systems and public transit; this relationship can promote the use of docked systems [43]. Future studies could empirically research individuals' travel behavior with dockless shared bikes and other travel modes to test the substitution or stimulation relationships between dockless bikeshare systems and walking or public transit. In addition, further investigation on users' travel satisfaction of this travel mode is needed to help encourage the adoption and usage of dockless bikeshare systems. 
Author Contributions: Conceptualization, Z.C., D.v.L., and D.E.; methodology, Z.C., D.v.L., and D.E.; software, Z.C.; validation, Z.C., D.v.L., and D.E.; formal analysis, Z.C.; investigation, Z.C.; resources, Z.C.; data curation, Z.C.; writing —original draft preparation, Z.C.; writing—review and editing, Z.C., D.v.L., and D.E.; visualization, Z.C.; supervision, D.v.L., and D.E.; project administration, D.E.; funding acquisition, Z.C. All authors have read and agreed to the published version of the manuscript.

Funding: This work was supported in part by grants from the Chinese Scholarship Council [grant number 201707720038].

Acknowledgments: The authors greatly acknowledge the support from Utrecht University's department of Human Geography and Spatial Planning.

Conflicts of Interest: The authors declare no conflict of interest.

\section{References}

1. DeMaio. Bike-sharing: History, impacts, models of provision, and future. J. Public Transp. 2009, 12, 3.

2. Shaheen, S.; Guzman, S.; Zhang, H. Bikesharing in Europe, the Americas, and Asia: Past, present, and future. Transp. Res. Rec. J. Transp. Res. Board 2010, 2143, 159-167. [CrossRef]

3. Mooney, S.J.; Hosford, K.; Howe, B.; Yan, A.; Winters, M.; Bassok, A.; Hirsch, J.A. Freedom from the station: Spatial equity in access to dockless bike share. J. Transp. Geogr. 2019, 74, 91-96. [CrossRef] [PubMed]

4. Shen, Y.; Zhang, X.; Zhao, J. Understanding the usage of dockless bike sharing in Singapore. Int. J. Sustain. Transp. 2018, 1-15. [CrossRef]

5. Sharing Economic Research Center. The Research Report on Bike-Sharing Employment. Available online: http://www.sic.gov.cn/News/568/8452.htm (accessed on 7 February 2020).

6. Fishman, E. Bikeshare: A Review of Recent Literature. Transp. Rev. 2015, 36, 92-113. [CrossRef]

7. Shaheen, S.A.; Martin, E.W.; Cohen, A.P.; Chan, N.D.; Pogodzinski, M. Public Bikesharing in North America During a Period of Rapid Expansion: Understanding Business Models, Industry Trends \& User Impacts. Available online: https://scholarworks.sjsu.edu/cgi/viewcontent.cgi?article=1070\&context=mti_publications (accessed on 7 February 2020).

8. Shaheen, S.; Cohen, A. Shared Micromoblity Policy Toolkit: Docked and Dockless Bike and Scooter Sharing. Available online: https://escholarship.org/uc/item/00k897b5 (accessed on 7 February 2020).

9. Buck, D.; Buehler, R.; Happ, P.; Rawls, B.; Chung, P.; Borecki, N. Are Bikeshare Users Different from Regular Cyclists? Transp. Res. Rec. J. Transp. Res. Board 2013, 2387, 112-119. [CrossRef]

10. Murphy, E.; Usher, J. The Role of Bicycle-sharing in the City: Analysis of the Irish Experience. Int. J. Sustain. Transp. 2014, 9, 116-125. [CrossRef]

11. Fishman, E.; Washington, S.; Haworth, N.; Mazzei, A. Barriers to bikesharing: An analysis from Melbourne and Brisbane. J. Transp. Geogr. 2014, 41, 325-337. [CrossRef]

12. Goodman, A.; Cheshire, J. Inequalities in the London bicycle sharing system revisited: Impacts of extending the scheme to poorer areas but then doubling prices. J. Transp. Geogr. 2014, 41, 272-279. [CrossRef]

13. Ogilvie, F.; Goodman, A. Inequalities in usage of a public bicycle sharing scheme: Socio-demographic predictors of uptake and usage of the London (UK) cycle hire scheme. Prev. Med. 2012, 55, 40-45. [CrossRef]

14. Shaheen, S.; Zhang, H.; Martin, E.; Guzman, S. Hangzhou Public Bicycle: Understanding Early Adoption and Behavioral Response to Bikesharing in Hangzhou, China. Transp. Res. Rec. J. Transp. Res. Board 2011, 2247, 33-41.

15. Xing, Y.; Handy, S.L.; Mokhtarian, P.L. Factors associated with proportions and miles of bicycling for transportation and recreation in six small US cities. Transp. Res. Part D Transp. Environ. 2010, 15, 73-81. [CrossRef]

16. de Geus, B.; De Bourdeaudhuij, I.; Jannes, C.; Meeusen, R. Psychosocial and environmental factors associated with cycling for transport among a working population. Health Educ. Res. 2008, 23, 697-708. [CrossRef] [PubMed]

17. Goodman, A.; Green, J.; Woodcock, J. The role of bicycle sharing systems in normalising the image of cycling: An observational study of London cyclists. J. Transp. Health 2014, 1, 5-8. [CrossRef] [PubMed]

18. Kaplan, S.; Wrzesinska, D.K.; Prato, C.G. The role of human needs in the intention to use conventional and electric bicycle sharing in a driving-oriented country. Transp. Policy 2018, 71, 138-146. [CrossRef]

19. Heinen, E.; Maat, K.; van Wee, B. The effect of work-related factors on the bicycle commute mode choice in the Netherlands. Transportation 2012, 40, 23-43. [CrossRef] 
20. Ma, L.; Dill, J. Associations between the objective and perceived built environment and bicycling for transportation. J. Transp. Health 2015, 2, 248-255. [CrossRef]

21. Fernández-Heredia, Á.; Monzón, A.; Jara-Díaz, S. Understanding cyclists' perceptions, keys for a successful bicycle promotion. Transp. Res. Part A Policy Pract. 2014, 63, 1-11. [CrossRef]

22. Festa, D.C.; Forciniti, C. Attitude towards Bike Use in Rende, a Small Town in South Italy. Sustainability 2019, 11, 2703. [CrossRef]

23. Ewing, R.; Cervero, R. Travel and the Built Environment. J. Am. Plan. Assoc. 2010, 76, 265-294. [CrossRef]

24. Heinen, E.; van Wee, B.; Maat, K. Commuting by Bicycle: An Overview of the Literature. Transp. Rev. 2010, 30,59-96. [CrossRef]

25. Pinjari, A.R.; Bhat, C.R.; Hensher, D.A. Residential self-selection effects in an activity time-use behavior model. Transp. Res. Part B Methodol. 2009, 43, 729-748. [CrossRef]

26. Cao, X.; Mokhtarian, P.L.; Handy, S.L. Examining the Impacts of Residential Self-Selection on Travel Behaviour: A Focus on Empirical Findings. Transp. Rev. 2009, 29, 359-395. [CrossRef]

27. Chatman, D.G. Residential Choice, the Built Environment, and Nonwork Travel: Evidence Using New Data and Methods. Environ. Plan. A 2009, 41, 1072-1089. [CrossRef]

28. Cervero, R.; Kockelman, K. Travel demand and the 3Ds: Density, diversity, and design. Transp. Res. Part D Transp. Environ. 1997, 2, 199-219. [CrossRef]

29. Heinen, E.; Maat, K.; van Wee, B. The role of attitudes toward characteristics of bicycle commuting on the choice to cycle to work over various distances. Transp. Res. Part D Transp. Environ. 2011, 16, 102-109. [CrossRef]

30. Shaheen, S.; Cohen, A.; Yelchuru, B.; Sarkhili, S.; Hamilton, B.A. Mobility on Demand Operational Concept Report (No. FHWA-JPO-18-611). Available online: https://rosap.ntl.bts.gov/view/dot/34258 (accessed on 7 February 2020).

31. Cervero, R.; Denman, S.; Jin, Y. Network design, built and natural environments, and bicycle commuting: Evidence from British cities and towns. Transp. Policy 2019, 74, 153-164. [CrossRef]

32. Rixey, R. Station-Level Forecasting of Bike Sharing Ridership: Station Network Effects in Three U.S. Systems. Transp. Res. Rec. J. Transp. Res. Board 2013, 2387, 46-55. [CrossRef]

33. Buck, D.; Buehler, R. Bike Lanes and Other Determinants of Capital Bikeshare Trips. In Proceedings of the 91st Transportation Research Board Annual Meeting, Washington, DC, USA, 22-26 January 2012.

34. Mobike Global; Beijing Tsinghua Tongheng Planning and Design Institute; China New Urbanization Research Institute. The Mobike White Paper: Bike-Share in the City. Available online: https://mobike.com/sg/blog/ post/mobikewhitepaper (accessed on 7 February 2020).

35. Du, M.; Cheng, L. Better Understanding the Characteristics and Influential Factors of Different Travel Patterns in Free-Floating Bike Sharing: Evidence from Nanjing, China. Sustainability 2018, 10, 1244. [CrossRef]

36. Noland, R.B.; Deka, D.; Walia, R. A Statewide Analysis of Bicycling in New Jersey. Int. J. Sustain. Transp. 2011, 5, 251-269. [CrossRef]

37. Beecham, R.; Wood, J. Exploring gendered cycling behaviours within a large-scale behavioural data-set. Transp. Plan. Technol. 2013, 37, 83-97. [CrossRef]

38. Beijing Municipal Comission of Transport. The Governance of Dockless Shared Bikes. Available online: http://jtw.beijing.gov.cn/zmhd/zxft/wqhg/201912/t20191209_1009844.html (accessed on 7 February 2020).

39. Beijing Municipal Administration of Quality and Technology Supervision. Design Code of Bus Stops and Stations. Available online: https://www.wenku365.com/p-95226.html (accessed on 7 February 2020).

40. Jäppinen, S.; Toivonen, T.; Salonen, M. Modelling the potential effect of shared bicycles on public transport travel times in Greater Helsinki: An open data approach. Appl. Geogr. 2013, 43, 13-24. [CrossRef]

41. Yang, X.-H.; Cheng, Z.; Chen, G.; Wang, L.; Ruan, Z.-Y.; Zheng, Y.-J. The impact of a public bicycle-sharing system on urban public transport networks. Transp. Res. Part A Policy Pract. 2018, 107, 246-256. [CrossRef]

42. Shaheen, S.; Martin, E.; Cohen, A. Public Bikesharing and Modal Shift Behavior: A Comparative Study of Early Bikesharing Systems in North America. Int. J. Transp. 2013, 1, 35-54. [CrossRef]

43. Nair, R.; Miller-Hooks, E.; Hampshire, R.C.; Bušić, A. Large-Scale Vehicle Sharing Systems: Analysis of Vélib'. Int. J. Sustain. Transp. 2012, 7, 85-106. [CrossRef]

(C) 2020 by the authors. Licensee MDPI, Basel, Switzerland. This article is an open access article distributed under the terms and conditions of the Creative Commons Attribution (CC BY) license (http://creativecommons.org/licenses/by/4.0/). 